\title{
Emerging treatment options for management of malignant ascites in patients with ovarian cancer
}

This article was published in the following Dove Press journal:

International Journal of Women's Health

2 August 2012

Number of times this article has been viewed

\author{
Ramez N Eskander \\ Krishnansu S Tewari \\ Division of Gynecologic Oncology, \\ Department of Obstetrics and \\ Gynecology, University of California \\ at Irvine, Irvine, CA, USA
}

\begin{abstract}
Malignant ascites affects approximately $10 \%$ of patients with recurrent epithelial ovarian cancer and is associated with troublesome symptoms, including abdominal pressure and distension, dyspnea, bloating, pelvic pain, and bowel/bladder dysfunction. To date, no effective therapy has been identified for the treatment of malignant ascites in patients with recurrent, advanced ovarian cancer. In this article, we discuss currently existing options for the treatment of ascites associated with ovarian cancer, and review the literature as it pertains to novel, targeted therapies. Specifically, preclinical and clinical trials exploring the use of the antiangiogenic agents, bevacizumab and vascular endothelial growth factor-trap, as well as the nonangiogenic agent, catumaxomab, will be reviewed. Despite current limitations in treatment, knowledge regarding management options in the palliation of ascites is critical to practicing physicians. Ultimately, as with all novel therapies, symptom relief and treatment goals must be weighed against patient discomfort and potentially significant adverse events.
\end{abstract}

Keywords: angiogenesis, ascites, epithelial ovarian cancer

\section{Introduction}

Epithelial ovarian cancer accounts for $25 \%$ of all malignancies affecting the female genital tract, and is the most lethal gynecologic malignancy. In 2012, there will be an estimated 22,280 new ovarian cancer cases in the US, with 15,500 deaths. ${ }^{1}$ Advanced epithelial ovarian cancer is traditionally managed with cytoreductive surgery, followed by combination platinum and taxane chemotherapy. ${ }^{2}$ Patients with advanced disease who undergo successful cytoreductive surgery with no gross residual disease have a median survival of just over 5 years after completion of adjuvant chemotherapy. ${ }^{3}$ However, despite aggressive treatment, the majority of these patients develop recurrent cancer, with selection of chemotherapy-resistant clones. ${ }^{4}$ The subset of patients that develops recurrent disease comprises a population that traditionally faces extended exposure to multiple cytotoxic chemotherapy regimens, dictated by their disease-free interval. ${ }^{5-8}$ Throughout this period, management of disease-associated morbidities becomes a priority in an effort to improve quality of life.

Malignant ascites, which affects approximately two-thirds of patients with epithelial ovarian, primary peritoneal, and fallopian tube cancer is common, and to date few effective therapies have been identified..$^{9}$ Importantly, ascites is associated with troublesome symptoms, including abdominal pressure and distension, dyspnea, bloating, pelvic pain, and bowel/bladder dysfunction. ${ }^{10}$ Malignant ascites is defined by the National Cancer Institute as an accumulation of fluid containing cancer cells in the abdomen. ${ }^{11}$ Unlike other solid malignancies, where ascites portends a universally poor prognosis,
Correspondence: Krishnansu S Tewar Division of Gynecologic Oncology, Department of Obstetrics and Gynecology, University of California Irvine, I0I The City Drive South, Building 56 Suite 260, Orange, CA 92868, USA Fax + I 7I4 4566632

Email ktewari@uci.edu 
patients with epithelial ovarian cancer and ascites at the time of diagnosis can expect 5-year survival rates approaching $40 \%{ }^{11,12}$ This discrepancy is largely attributable to the biology of ovarian cancer, and subsequent etiology of abdominal fluid accumulation. Specifically, malignant ascites in patients with epithelial ovarian cancer is thought to be attributable to lymphatic obstruction, increased vascular permeability release of inflammatory cytokines, and a direct increase of fluid production by the cancer cells lining the peritoneal cavity. ${ }^{13,14}$

Upfront treatment of patients with advanced epithelial ovarian cancer, irrespective of the presence or absence of ascites, relies on a combination of aggressive cytoreductive surgery and adjuvant chemotherapy. The goal of surgical cytoreduction is to reduce disease burden to $\leq 1 \mathrm{~cm}$ (defined as optimal cytoreduction by the Gynecologic Oncology Group). As a result of optimal cytoreduction, these patients experience effective control of their ascites. Unfortunately, despite improvement in surgical management, only a small fraction of patients are cured following primary surgery and chemotherapy, with greater than $75 \%$ experiencing disease recurrence. Repeat attempts at surgical excision are only performed in selected patients with prolonged disease-free intervals, localized disease recurrence, and good performance status. The remaining patients are managed with systemic therapies. Accumulation of ascites affects patients with progressive disease or treatment failure, and must be managed in order to maintain overall quality of life. ${ }^{15}$

Historically, malignant ascites in patients with epithelial ovarian cancer was treated utilizing diuretics, salt restriction, and intraperitoneal administration of sclerosing agents and radioactive isotopes. ${ }^{16,17}$ Patients with malignant ascites secondary to epithelial ovarian cancer rarely suffer from fluid accumulation due to intraparenchymal liver metastasis, and portal hypertension is rarely identified. Rather, these patients traditionally exhibit reduced intravascular volume, making use of diuretics an unattractive option. ${ }^{18}$ With respect to the use of radioactive isotopes, poor tumor penetration and intestinal toxicity (necrosis and perforation) due to loculations and prolonged exposure have caused them to fall out of favor. Limited success rates, in combination with significant side effects, have resulted in infrequent use of these modalities.

Mechanical drainage of accumulated ascetic fluid via therapeutic paracentesis results in relief in up to $90 \%$ of patients. ${ }^{19}$ However, recurrence/reaccumulation of ascites is common, and multiple paracenteses are required, with their associated risks of pain, visceral perforation, infection, and formation of hematoma. ${ }^{11,20}$ Furthermore, these patients are likely to have intra-abdominal adhesions as a result of extensive surgical cytoreduction, and the resultant fluid loculations limit the therapeutic benefit derived. ${ }^{21}$ Alternatively, placement of permanent intra-abdominal drains and peritoneovenous shunts has been explored. Experience with these modalities has been poor, with blockage of the shunt, infectious morbidity, as well as embolization and implantation of tumor cells in distant organs reported to be relatively common complications. ${ }^{17,22-25}$

Given the above, exploration of innovative approaches for the treatment of malignant ascites in patients with advanced epithelial ovarian cancer has been a clinical priority. With advances in our understanding of cancer biology, novel therapeutic targets have been identified. Specifically, the relationship between angiogenesis and epithelial ovarian cancer has been elucidated over the last decade, and strategies developed to interfere with this process have shown promise in the control of ascites associated with epithelial ovarian cancer. This mini review article discusses the role of emerging therapies targeting angiogenesis in the management of ascites, and summarizes the currently available data in the literature.

\section{Angiogenesis and ascites}

Under normal homeostatic conditions, excluding wound healing and embryonic development, a balance exists between proangiogenic and antiangiogenic signals, resulting in a quiescent vascular environment. However, within the tumor microenvironment, aberrant signaling has been shown to favor the proangiogenic cascade, resulting in formation of new vessels. ${ }^{26,27}$ The formation of new blood vessels, a process termed angiogenesis, is essential for tumor growth beyond $1-2 \mathrm{~mm}^{3}$. This process is mediated via the vascular endothelial growth factor (VEGF) family of growth factors and receptors, and is believed to be essential for tumor growth and ascites formation. Furthermore, these tumor vessels, formed under the influence of VEGF, are disorganized, tortuous, and leaky. ${ }^{28}$ Inhibition of VEGF-mediated signaling leads to "normalization" of this tumor vasculature, as well as improved oxygen, nutrient and chemotherapy delivery, and is believed to result in increased tumor toxicity and decreased formation of ascites fluid. ${ }^{8}$

VEGF expression has been repeatedly demonstrated in epithelial ovarian cancer tissue specimens, and the degree of expression of VEGF and its receptors has been shown to correlate with a poor prognosis. ${ }^{29,30}$ VEGF-A (commonly known and referred to as VEGF) was first identified and cloned in $1989 .{ }^{31}$ In a series of molecular biology and animal model studies, VEGF was noted to be a potent mitogen for 
endothelial cells in vitro and acted as an angiogenic molecule in vivo. In addition to VEGF, the VEGF family is composed of VEGF-B, VEGF-C, VEGF-D, VEGF-E, and the placental growth factors, PlGF-1 and PlGF-2. ${ }^{32-34}$ The most important member of this group is VEGF itself, which appears to play a principal role in angiogenesis.

VEGF binds to and interacts with a series of receptor tyrosine kinases known as VEGFR-1, VEGFR-2, and VEGFR-3, as well as accessory receptors known as neuropilins. ${ }^{35}$ It appears that signal transduction through VEGFR-2 mediates the permeability actions of VEGF, as evidenced by the fact that VEGFR-2 gene knockout mice fail to develop vasculature and have sparse endothelial cells. ${ }^{36}$ It is hypothesized that as cancerous cells multiply and the tumor mass grows, there is secretion of VEGF, promoting neovascularization, allowing for nutrient delivery, and facilitating metastasis. In cases of disseminated intra-abdominal metastatic disease, both increased production of peritoneal fluid by the cancer cells, and increased microvascular permeability result in significant ascites. In addition, investigators have shown increased VEGF protein levels in malignant ascites compared with levels in nonmalignant cirrhotic controls. ${ }^{37}$

\section{VEGF inhibition for treatment of malignant ascites VEGF-specific monoclonal antibody}

Given the apparent dependence of ascites formation on abnormal tumor vascularity and permeability, it was hypothesized that VEGF inhibitors would show efficacy in the treatment of ascites associated with ovarian cancer (Figure 1). In preclinical nude mouse models of advanced ovarian cancer, inhibition of VEGF signaling was associated with a marked decrease in ascites formation and tumor burden. ${ }^{38-40}$ Furthermore, it has been shown that malignant effusions derived from tumorbearing mice and guinea pigs contain high concentrations of VEGF. ${ }^{41}$ VEGF production by cancer cells has been shown to correlate directly with tumor-cell induced production of ascites in animal models. ${ }^{41}$ Strikingly, direct transfection of mouse peritoneum with VEGF alone is sufficient to cause accumulation of peritoneal effusions.

This strong preclinical evidence catalyzed the investigation of bevacizumab for the palliation of symptomatic ascites in patients with heavily pretreated recurrent ovarian carcinoma (Table 1). ${ }^{42}$ Numnum et al described four patients with recurrent ovarian cancer and ascites requiring frequent paracentesis who were treated with intravenous bevacizumab at a dose of $15 \mathrm{mg} / \mathrm{kg}$ every 3 weeks. All four patients demonstrated symptomatic relief of ascites, with manageable toxicity. No therapeutic paracenteses were required after initiation of treatment with bevacizumab (follow-up of up to 6 months). ${ }^{42}$

In an analogous manner, Hamilton et al described a case report detailing the impact of intraperitoneal bevacizumab $(5 \mathrm{mg} / \mathrm{kg})$ on severe symptomatic ascites in an elderly patient with advanced, recurrent ovarian cancer and very poor functional status. ${ }^{43}$ The authors reported a dramatic improvement

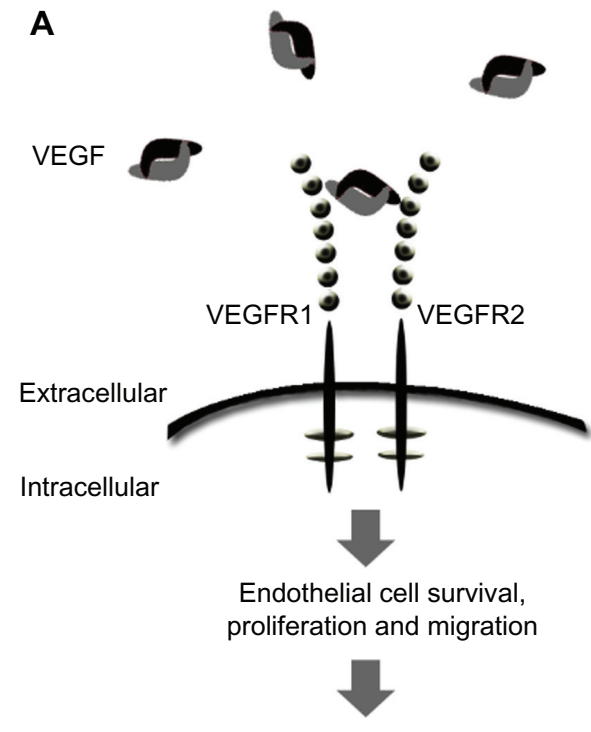

Angiogenesis and ascites
B

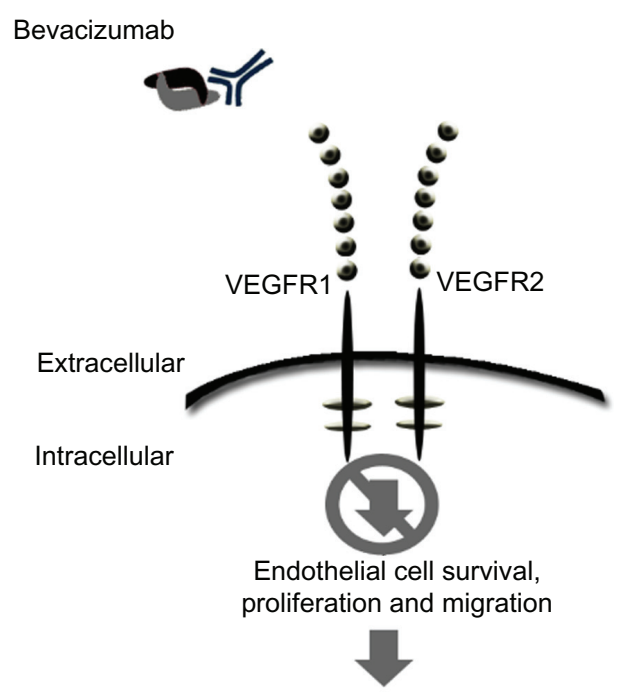

Angiogenesis and ascites

Figure I Schematic of mode of action for VEGF signaling and bevacizumab. (A) Free unbound VEGF interacting with the receptor. (B) The monoclonal antibody, bevacizumab, binds to VEGF-A, preventing ligand-receptor interaction and downstream signaling. Abbreviation: VEGF, vascular endothelial growth factor. 
Table I Studies reporting use of bevacizumab for treatment of ascites associated with ovarian cancer

\begin{tabular}{|c|c|c|c|c|c|}
\hline Study & $\mathbf{n}$ & Drug dose & $\begin{array}{l}\text { Route } \\
\text { of administration }\end{array}$ & Best response & Toxicity \\
\hline $\begin{array}{l}\text { El Shami } \\
\left(\text { ASCO 2007) }^{61}\right.\end{array}$ & 9 & $5 \mathrm{mg} / \mathrm{kg}$ monthly & IP & $\begin{array}{l}\text { All subjects with resolution of ascites } \\
\text { over } 2 \text {-month observation period }\end{array}$ & $\begin{array}{l}\text { Grade I nausea; grade I abdominal } \\
\text { pain; small bowel obstruction* }\end{array}$ \\
\hline Numnum et $\mathrm{al}^{42}$ & 4 & $15 \mathrm{mg} / \mathrm{kg}$ every 3 weeks & IV & $\begin{array}{l}\text { No paracentesis required during } \\
\text { 6-month study period for all subjects }\end{array}$ & $\begin{array}{l}\text { Grade I HTN; grade } 2 \text { proteinuria } \\
\text { and HTN }\end{array}$ \\
\hline Hamilton et al ${ }^{43}$ & 1 & $5 \mathrm{mg} / \mathrm{kg} \times 2$ treatments & IP & $\begin{array}{l}\text { Resolution of ascites for } 18 \text { days } \\
\text { (until death) }\end{array}$ & None reported \\
\hline Kesterson et $\mathrm{al}^{44}$ & I & $15 \mathrm{mg} / \mathrm{kg}$ every 3 weeks & IV & Ascites relief for 6 months & No bevacizumab-related toxicities \\
\hline
\end{tabular}

Note: *Resolved with conservative management.

Abbreviations: ASCO, American Society of Clinical Oncology; n, number of subjects; IP, intraperitoneally; IV, intravenously; HTN, hypertension.

in ascites and quality of life parameters following two doses. Two additional case reports described the off-label use of bevacizumab in 10 patients with refractory ascites and significant disease burden. ${ }^{44}$ Relief of ascites was seen in all subjects, lasting 2-6 months. ${ }^{41}$ The largest of these reports, described by El Shami et $\mathrm{a}^{61}{ }^{61}$ investigated the efficacy and safety of bevacizumab $(5 \mathrm{mg} / \mathrm{kg}$ administered intraperitoneally every 4 weeks) in nine patients with refractory ascites secondary to colorectal, breast, uterine, and ovarian cancer. ${ }^{41}$ Remarkably, the malignant ascites resolved in all treated patients after a single dose, without reaccumulation over a median observation period of more than 2 months.

\section{VEGF-trap}

VEGF-trap, a fusion protein that prevents VEGF receptor binding, has also been studied in the treatment of refractory ascites. In contrast with the antibody-based VEGF binding strategy used by bevacizumab, VEGF-trap, or aflibercept, incorporates the second binding domain of the VEGFR-1 receptor and the third domain of the VEGFR-2 receptor (Figure 2). ${ }^{45}$ By fusing these extracellular protein sequences to the Fc segment of a human IgG backbone, developers created a chimeric protein with a very high VEGF binding affinity, binding all isomers of the VEGF-A family. ${ }^{45,46}$ Of note, it has also been shown to bind VEGF-B and placental growth factor, with uncertain clinical implications.

Preclinical xenograft animal models have shown that VEGF-trap is effective in inhibiting tumor growth and angiogenesis, reducing blood vessel density, inhibiting metastasis, and improving survival..$^{38,47,48} \mathrm{Hu}$ et al investigated the impact of VEGF-trap on ascites formation in a mouse model of ovarian cancer. ${ }^{49}$ Following intraperitoneal administration of VEGF-trap and paclitaxel, complete resolution of ascites was noted, with a $98 \%$ reduction in tumor burden. Furthermore, no measurable ascites developed in the population treated with VEGF-trap. Tumor vessel imaging showed sparse, short vessels in treated mice as compared with controls, in which vessels were numerous, irregular, tortuous, and leaky. ${ }^{49}$

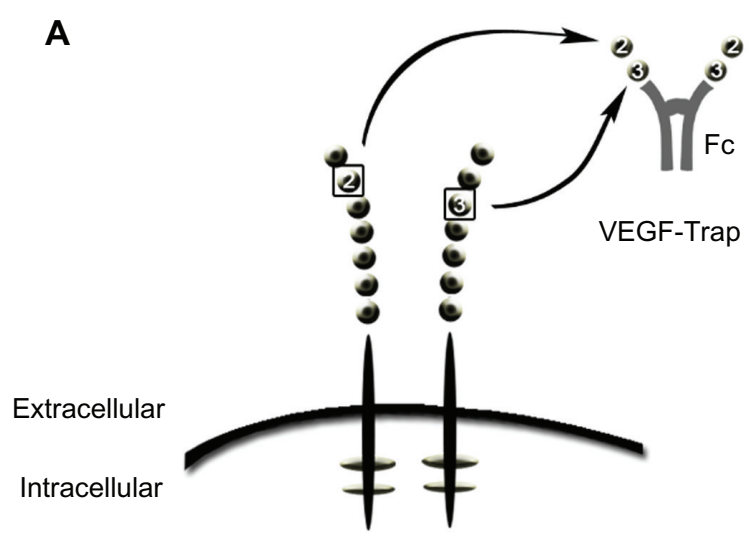

VEGFR1 VEGFR2
B

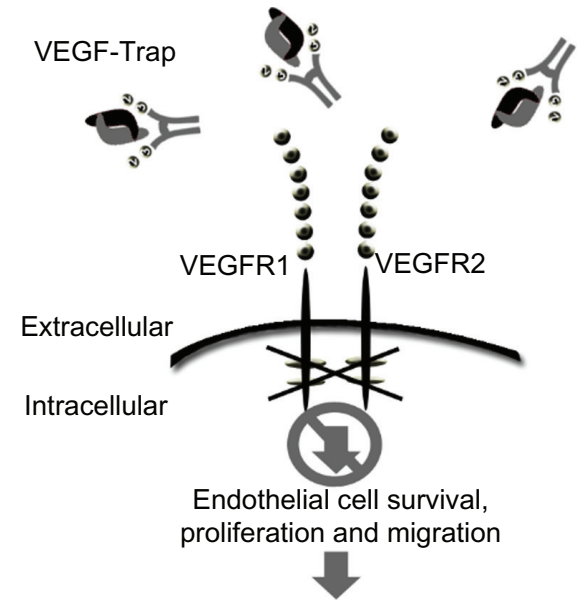

Angiogenesis and ascites

Figure 2 Schematic of VEGF-trap mode of action. VEGF-trap is a fusion protein that prevents VEGF-receptor binding. (A) VEGF-trap, or aflibercept, incorporates the second binding domain of the VEGFR-I receptor and the third domain of the VEGFR-2 receptor. (B) This chimeric protein has a high VEGF binding affinity, preventing VEGF-receptor interaction and downstream signaling.

Abbreviation: VEGF, vascular endothelial growth factor. 
In 2003, Byrne et al reported that single-agent aflibercept significantly reduced both ascites and tumor burden in experimental models of ovarian cancer. ${ }^{38}$

The safety and tolerability of VEGF-trap were evaluated in a Phase I clinical trial conducted by Lockhart et al. ${ }^{50}$ A total of 47 patients (14 of whom had ovarian, peritoneal, or fallopian tube cancer) were enrolled from two institutions. The dose ranged from $0.3 \mathrm{mg} / \mathrm{kg}$ to $7.0 \mathrm{mg} / \mathrm{kg}$ given intravenously every 2 weeks. The most common adverse events were fatigue, nausea, and vomiting. Within this cohort, three partial responses were observed according to RECIST (Response Evaluation Criteria in Solid Tumors) criteria, one at the $3.0 \mathrm{mg} / \mathrm{kg}$ and two at the $7.0 \mathrm{mg} / \mathrm{kg}$ dose level. The authors concluded that VEGF-trap, when administered intravenously, was well tolerated at the dose levels tested. ${ }^{50}$

Several single-agent and combination Phase II clinical trials have explored the safety and efficacy of VEFG-trap in the treatment of ascites associated with advanced solid tumors, including ovarian cancer. ${ }^{51,52}$ Two recently published trials investigated the use of VEGF-trap in the treatment of advanced epithelial ovarian cancer and symptomatic malignant ascites.

Colombo et al enrolled 16 patients with advanced chemoresistant epithelial ovarian cancer and symptomatic malignant ascites into an open-label Phase II trial assessing the efficacy and safety of aflibercept. ${ }^{53}$ Patients who required $\geq 3$ previous paracenteses at 1-4 paracenteses per month received intravenous aflibercept at a dose of $4 \mathrm{mg} / \mathrm{kg}$ every 2 weeks. The primary endpoint was repeat paracentesis response rate, with response defined as at least a two-fold increase in time to repeat paracentesis compared with the baseline interval. Ten of the 16 enrolled patients achieved a response; the repeat paracentesis response rate was $62.5 \%$ (95\% confidence interval 35.4-84.8, Table 2) in these patients. Aflibercept was considered effective based on a hypothesis that the repeat paracentesis response rate was $\geq 60 \%$. Median time to repeat paracentesis was 76.0 days (95\% confidence interval 64.0-178.0), which was 4.5 times longer than the baseline interval (16.8 days, Figure 4). Adverse events reported as part of the study included hypertension (seven patients), headache, anorexia, and dysphonia (three patients each). ${ }^{53}$ Only two subjects experienced grade 3/4 treatment-related adverse events, ie hypertension and weight loss, and one patient developed intestinal perforation.

A similar study conducted by Gotlieb et al specifically explored treatment of malignant ascites in patients with advanced epithelial ovarian cancer using aflibercept. ${ }^{54}$ In this double-blind, placebo-controlled, parallel-group,
Table 2 Summary of efficacy endpoints

Total number

of patients $(n=16)$

\begin{tabular}{ll}
\hline Primary endpoints & \\
Repeat paracentesis response, & 62.5 \\
$\quad$ Number of responders, \% & $35.4-84.8$ \\
$95 \%$ exact Cl & \\
Secondary endpoints & $67.7(59.9)[35.8-99.6]$ \\
Time to repeat paracentesis, days & $50.5(12-180)$ \\
$\quad$ Mean (SD) [95\% Cl] & $76.0[64.0-178.0]$ \\
Median (range) & \\
Median [95\% Cl] & \\
$60-$ day frequency of paracentesis, $\mathrm{n}(\%)$ & $1.5(1.6)[0.63-2.36]$ \\
$\quad$ Mean (SD) [95\% Cl] & $1.4(0-5)$ \\
$\quad$ Median (range) & $59.5[41.0-83.0]$ \\
Progression-free survival, days & \\
$\quad$ Median [95\% Cl] & \\
Overall survival, days & $92.0[58.0-\mathrm{NC}]$ \\
$\quad$ Median [95\% Cl] & \\
\hline
\end{tabular}

Note: aBased on Kaplan-Meier estimates.

Copyright (๑) 2012. Elsevier. Adapted with permission from Colombo N, Mangili G, Mammoliti S, et al. A Phase II study of aflibercept in patients with advanced epithelial ovarian cancer and symptomatic malignant ascites. Gynecol Oncol. 2012; 125(1):42-47. ${ }^{53}$

Abbreviations: $\mathrm{Cl}$, confidence intervals; $\mathrm{NC}$, not calculable; SD, standard deviation.

Phase II study, patients with advanced chemoresistant ovarian cancer and recurrent symptomatic malignant ascites were randomly assigned to receive either intravenous aflibercept ( $4 \mathrm{mg} / \mathrm{kg}$ every 2 weeks) or placebo, stratified according to time interval ( $\leq 2$ weeks versus $>2$ weeks) between the two most recent paracenteses before randomization. ${ }^{54}$ The primary efficacy endpoint was time to repeat paracentesis. A total of 55 patients with a median of four (range 2-11) previous lines of chemotherapy were randomly assigned to receive placebo $(n=26)$ or aflibercept $(n=29)$. Mean time to repeat paracentesis was significantly longer with aflibercept than with placebo (55.1 versus 23.3 days; difference 31.8 days, $95 \%$ confidence interval 10.6-53.1; $P=0.0019$ ). Notably, in the aflibercept group, two patients did not need a repeat paracentesis during six months of double-blind treatment. In this subset of heavily pretreated patients with advanced ovarian cancer, three gastrointestinal perforations were noted in the aflibercept group, and one intestinal fistula was identified in the placebo group.

\section{Nonangiogenic targeted therapies used for malignant ascites Trifunctional antibody catumaxomab}

In addition to the VEGF-directed antibodies, bevacizumab and VEGF-trap, alternate targeted agents have been investigated in the treatment of ascites. Catumaxomab is a trifunctional monoclonal antibody with two different 
antigen-binding sites and a functional Fc domain. ${ }^{55,56}$ The two specific antigen-binding sites bind to epithelial tumor cells via the epithelial cell-adhesion molecule (EpCAM) and to $\mathrm{T}$ cells via $\mathrm{CD} 3$. In addition, catumaxomab activates $\mathrm{Fc} \gamma$ receptor I-positive, IIa-positive, and III-positive accessory cells (dendritic cells, macrophages, and natural cells) via its functional Fc domain (Figure 3). ${ }^{55,56}$

The functionality and selectivity of this novel antibody rely on the fact that tumor cells in effusions associated with malignant ovarian cancer have been shown to express EpCAM in $70 \%-100 \%$ of cases, while the mesothelial cells lining the peritoneal cavity lack expression. ${ }^{57}$ Following binding with EpCAM, catumaxomab recruits and activates of immune effector cells, resulting in its antineoplastic activity.

Intraperitoneal administration of catumaxomab was first studied in the treatment of eight patients (two of whom had ovarian cancer) with malignant ascites in $2005 .{ }^{58}$ All patients had $>2 \%$ EpCAM expression via flow cytometry on nuclear ascites cells. Trifunctional antibodies were administered intraperitoneally over 6-8 hours for at least four cycles. Seven of eight patients required no further paracentesis during follow-up or until death, with a mean paracentesisfree interval of 38 weeks (median 21.5, range 4-136). A clinical response with disappearance of ascites was seen in all patients, and correlated with elimination of tumor cells $(P=0.0014) .^{58}$

Following this study, a multicenter Phase I/II clinical trial was conducted evaluating the tolerability and efficacy of intraperitoneal catumaxomab in ovarian cancer patients with malignant ascites containing EpCAM-positive tumor cells. ${ }^{59}$ Twenty-three women with recurrent ascites due to pretreated refractory ovarian cancer were treated with 4-5 intraperitoneal infusions of catumaxomab at doses of 5-200 $\mu \mathrm{g}$ over 9-13 days. Treatment with catumaxomab resulted in significant and sustained reduction of ascites. Twenty-two of 23 patients did not require paracentesis between the last infusion and the end of the study at day $37 .{ }^{59}$ The most commonly reported grade $2 / 3$ adverse events in the study were fever, nausea, and vomiting.

Recently, a prospective, randomized Phase II/III study was conducted comparing the efficacy of catumaxomab plus paracentesis with paracentesis alone in the treatment of malignant ascites. ${ }^{57}$ Following paracentesis, catumaxomab was administered at doses of $10,20,50$, and $150 \mu \mathrm{g}$ on days $0,3,7$, and 10 , respectively, via an intraperitoneal catheter. The primary efficacy endpoint was puncture-free survival. Secondary efficacy parameters included time to next paracentesis, signs and symptoms of ascites, and overall survival. Puncture-free survival was significantly longer in the catumaxomab group (median 46 days) than in the control group (median 11 days, hazards ratio 0.254; $P<0.0001$ ), as was the median time to next paracentesis ( 77 versus 13 days; $P<0.0001$, Figure 5). Within the ovarian cancer cohort, median puncture-free survival was 52 days in the catumaxomab arm versus 11 days in the placebo arm (hazards ratio 0.205; $P<0.0001)$. In addition, catumaxomab patients had fewer signs and symptoms of ascites than control patients. The most common adverse events included fever, abdominal pain, nausea, and vomiting (Table 3 ). One patient had a grade 3 gastric hemorrhage. Findings from the above trials ultimately resulted in approval by the European Medicines Agency for catumaxomab for the treatment of malignant ascites in patients with EPCAM-positive tumors for whom no standard therapy is available. ${ }^{13}$

Given the mouse-rat origin of catumaxomab, limitations in retreatment were anticipated due to formation of human
A

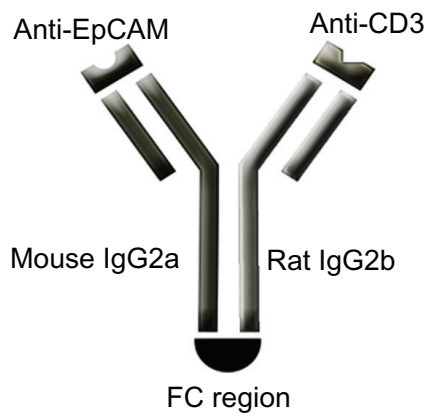

B

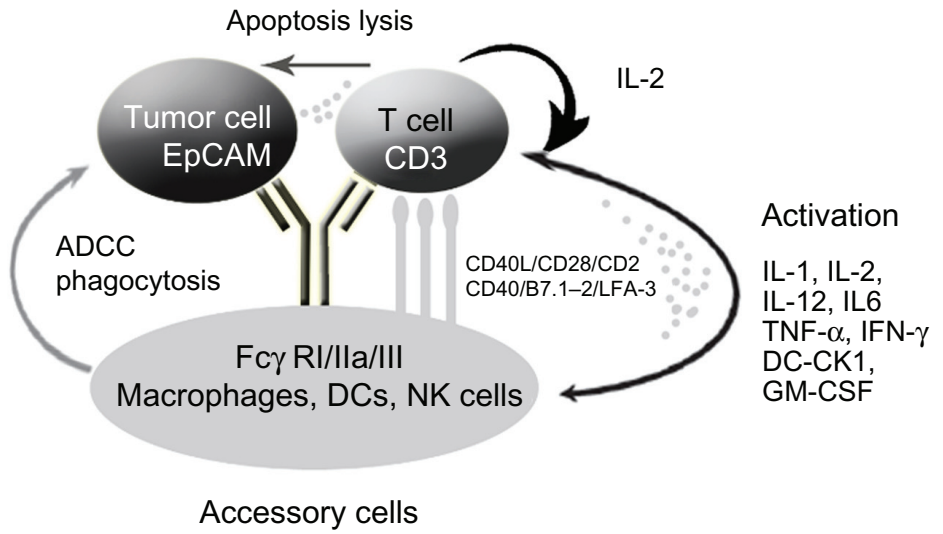

Figure 3 Schematic of mode of action of catumaxomab. (A) Catumaxomab is a trifunctional monoclonal antibody with two different antigen-binding sites and a functional Fc domain. (B) The two specific antigen-binding sites bind to epithelial tumor cells via the epithelial cell-adhesion molecule (EpCAM) and to T cells via CD3, while activating Fc $\gamma$ receptor I-positive, Ila-positive, and III-positive accessory cells (dendritic cells, macrophages and natural killer cells) via its functional Fc domain. 


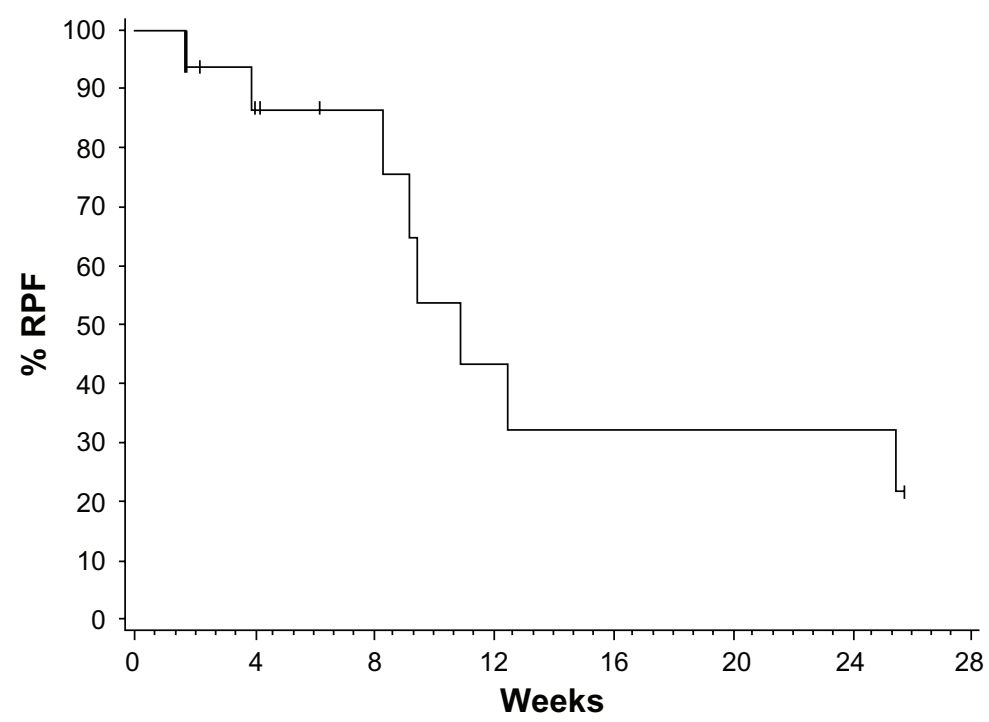

\section{Number at risk}

12

8

4

3

3

3

Figure 4 Kaplan-Meier plot of time to repeat paracentesis in patients treated with VEGF-trap (aflibercept) for the management of malignant ascites. Median time to repeat paracentesis was 76.0 days (95\% confidence interval 64.0-178.0), which was 4.5 times longer than the baseline interval ( 16.8 days) in the aflibercept group.

Copyright ( 2 2012. Elsevier. Adapted with permission from Colombo N, Mangili G, Mammoliti S, et al. A Phase II study of aflibercept in patients with advanced epithelial ovarian cancer and symptomatic malignant ascites. Gynecol Oncol. 20I2; I25(I):42-47. ${ }^{53}$

Abbreviation: VEGF, vascular endothelial growth factor.
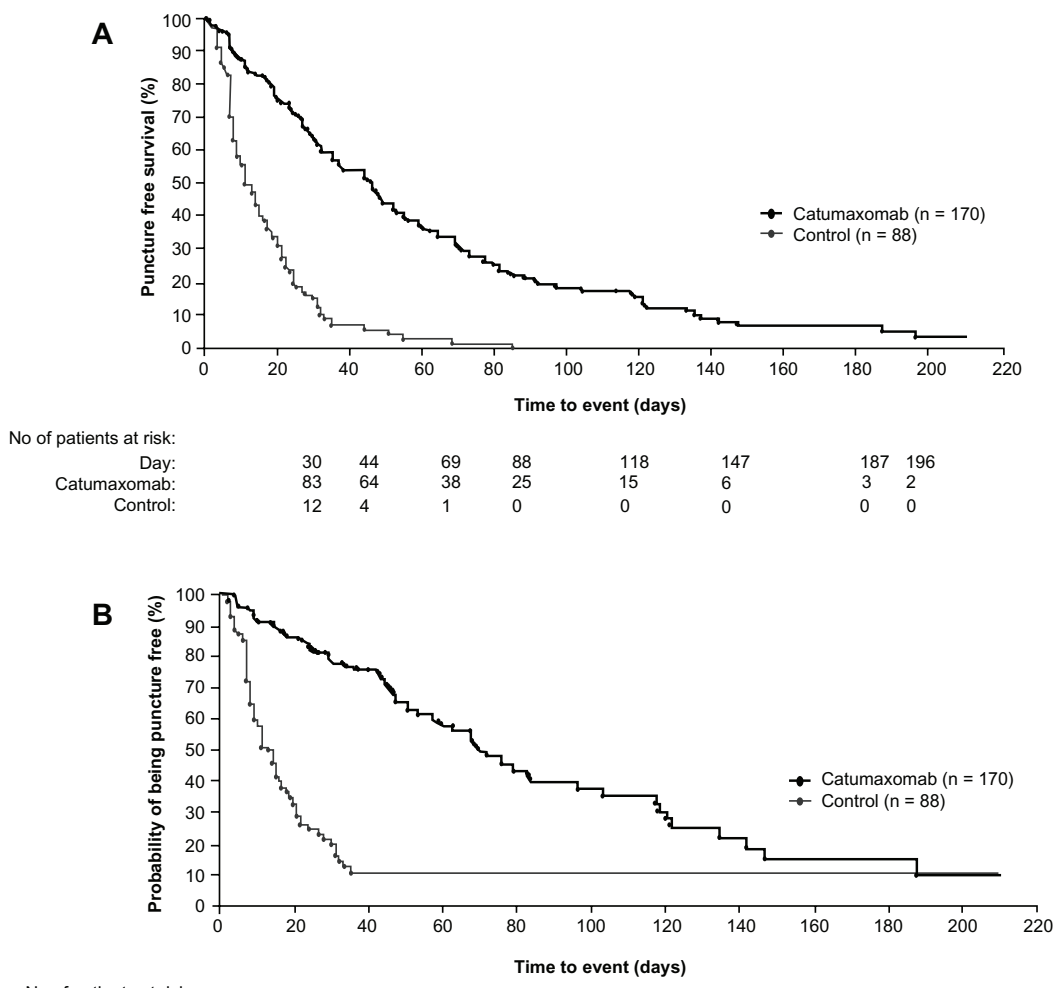

$\begin{array}{rrllllll}\text { No of patients at risk: } & & & & & & & \\ \text { Day: } & 3035 & 70 & 85 & 104 & 122 & 147 & 187 \\ \text { Catumaxomab: } & 8175 & 37 & 26 & 18 & 11 & 6 & 3 \\ \text { Control: } & 125 & 5^{*} & 5^{*} & 5^{*} & 5^{*} & 5^{*} & 5^{*} \\ & & & & & & & \end{array}$

Figure 5 Kaplan-Meier estimates of puncture-free survival and time to next paracentesis in both the catumaxomab and control populations. (A) Puncture-free survival in the pooled population. (B) Time to next paracentesis in the pooled population.

Copyright @ 2010. John Wiley and Sons. Adapted with permission from Heiss MM, Murawa P, Koralewski P, et al. The trifunctional antibody catumaxomab for the treatment of malignant ascites due to epithelial cancer: Results of a prospective randomized Phase II/III trial. Int J Cancer. 2010;127(9):2209-2221. ${ }^{57}$ 
Table 3 Summary of adverse events related to catumaxomab occurring in $\geq 5 \%$ of subjects

\begin{tabular}{lll}
\hline & \multicolumn{2}{l}{ Number of patients (\%) } \\
\cline { 2 - 3 } & All grades & Grade $\geq \mathbf{3}^{1}$ \\
\hline Pyrexia & $95(60.5)$ & $9(5.7)$ \\
Abdominal pain & $67(42.7)$ & $15(9.6)$ \\
Nausea & $52(33.1)$ & $5(3.2)$ \\
Vomiting & $43(27.4)$ & $4(2.5)$ \\
Lymphopenia & $22(14.0)$ & $11(7.0)$ \\
C-reactive protein increased & $23(14.6)$ & $7(4.5)$ \\
Chills & $21(13.4)$ & $2(1.3)$ \\
Gamma-glutamyltranferase increased & $18(11.5)$ & $9(5.7)$ \\
Fatigue & $17(10.8)$ & $5(3.2)$ \\
Diarrhea & $16(10.2)$ & $3(1.9)$ \\
Leukocytosis & $16(10.2)$ & $2(1.3)$ \\
Tachycardia & $15(9.6)$ & $1(0.6)$ \\
Anorexia & $14(8.9)$ & $5(3.2)$ \\
Blood alkaline phosphatase increased & $14(8.9)$ & $4(2.5)$ \\
Anemia & $14(8.9)$ & $2(1.3)$ \\
Hypotension & $13(8.3)$ & $3(1.9)$ \\
Aspartate aminotransferase increased & $12(7.6)$ & $4(2.5)$ \\
Alanine aminotransferase increased & $10(6.4)$ & $3(1.9)$ \\
lleus & $10(6.4)$ & $5(3.2)$ \\
Pain & $8(5.1)$ & 0 \\
\hline Ne &
\end{tabular}

Notes: 'Symptomatic National Cancer Institute Common Toxicity Criteria ( $\mathrm{NCl}-$ CTC, version 2.0, April 30, 1999) Grade 4 events were observed as isolated cases. Copyright (C) 2010. John Wiley and Sons. Adapted with permission from Heiss MM, Murawa P, Koralewski P, et al. The trifunctional antibody catumaxomab for the treatment of malignant ascites due to epithelial cancer: Results of a prospective randomized Phase II/III trial. Int J Cancer. 2010;127(9):2209-2221.57

antidrug antibodies. However, in 2011, Pietzner et al described a case of successful retreatment with catumaxomab for the management of malignant ascites. ${ }^{60}$ A 74-year-old female patient with breast cancer and ascites associated with peritoneal carcinomatosis was treated with catumaxomab, with resolution of her symptoms. The patient remained puncturefree for 45 days, and evaluation of human antidrug antibody levels demonstrated increased levels after cycle 1, followed by a considerable decline and a delayed increase in ascites for each subsequent cycle. This experience suggested that a repeat cycle of catumaxomab might be feasible and effective in patients suffering from recurrent malignant effusions.

\section{Conclusion}

Malignant abdominal effusions affect a significant proportion of patients suffering from advanced ovarian cancer, and are associated with troubling symptoms including abdominal pain, dyspnea, bloating, weight loss, and bowel and bladder dysfunction. The biology of the disease and its propensity for peritoneal spread are unique, predisposing patients to formation of ascites. To date, no consensus has been reached regarding the treatment of ascites in patients with ovarian cancer. Traditional treatment methods, including salt restriction, diuretics, sclerosing agents, radioactive isotopes, paracentesis, and shunt placement, have shown limited and variable efficacy with significant toxicities.

More recently, targeted therapies have emerged as promising alternatives for the management of malignant effusions. Our understanding of the contribution of angiogenesis to ascites formation has resulted in the study of the antiangiogenic antibodies, bevacizumab and VEGF-trap, which have shown clinical efficacy in cohorts of heavily pretreated patients. In addition, the trifunctional antibody, catumaxomab, has shown positive signals in the treatment of malignant ascites. Ultimately, as with all novel therapies, symptom relief and treatment goals must be weighed against patient discomfort and potentially lethal adverse events. Careful patient selection and identification of risk factors to help reduce significant side effects associated with treatment are required. Further comparative studies and quality of life assessments are warranted before incorporation of these agents into daily practice.

\section{Acknowledgment}

We would like to thank Toa Ji for his artistic and digital imaging expertise, which were essential for the creation of the figures in this manuscript.

\section{Disclosure}

The authors have no conflicts of interest to disclose in this work.

\section{References}

1. Siegel R, Naishadham D, Jemal A. Cancer statistics, 2012. CA Cancer J Clin. 2012;62(1):10-29.

2. Bookman M. Trials with impact on clinical management: first line. Int J Gynecol Cancer. 2009;19 Supp1 2:S55-S62.

3. Ozols R, Bundy B, Greer B, et al. Phase III trial of carboplatin and paclitaxel compared with cisplatin and paclitaxel in patients with optimally resected stage III ovarian cancer: a Gynecologic Oncology Group study. J Clin Oncol. 2003;21(17):3194-3200.

4. Monk B, Choi D, Pugmire G, Burger R. Activity of bevacizumab (rhuMAB VEGF) in advanced refractory epithelial ovarian cancer. Gynecol Oncol. 2005;96(3):902-905.

5. Cannistra S. Evaluating new regimens in recurrent ovarian cancer: how much evidence is good enough? J Clin Oncol. 2010;28(19): 3101-3103.

6. Pujade-Lauraine E, Wagner U, Aavall-Lundqvist E, et al. Pegylated liposomal doxorubicin and carboplatin compared with paclitaxel and carboplatin for patients with platinum-sensitive ovarian cancer in late relapse. J Clin Oncol. 2010;28(20):3323-3329.

7. Cannistra S. Is there a "best" choice of second-line agent in the treatment of recurrent, potentially platinum-sensitive ovarian cancer? J Clin Oncol. 2002;20(5):1158-1160.

8. Eskander RN, Randall LM. Bevacizumab in the treatment of ovarian cancer. Biologics. 2011;5:1-5.

9. Malayev Y, Levene R, Gonzalez F. Palliative chemotherapy for malignant ascites secondary to ovarian cancer. Am J Hosp Palliat Care. February 23, 2012. [Epub ahead of print.] 
10. Loggie BW, Perini M, Fleming RA, Russell GB, Geisinger K. Treatment and prevention of malignant ascites associated with disseminated intraperitoneal malignancies by aggressive combined-modality therapy. Am Surg. 1997;63(2):137-143.

11. Barni S, Cabiddu M, Ghilardi M, Petrelli F. A novel perspective for an orphan problem: old and new drugs for the medical management of malignant ascites. Crit Rev Oncol Hematol. 2011;79(2): 144-153.

12. Jemal A, Siegel R, Xu J, Ward E. Cancer Statistics, 2010. CA Cancer J Clin. 2010;60(5):277-300.

13. Becker G, Blum HE. VEGF trap for the treatment of malignant ascites. Lancet Oncol. 2012;13(2):115-116.

14. Garrison RN, Galloway RH, Heuser LS. Mechanisms of malignant ascites production. $J$ Surg Res. 1987;42(2):126-132.

15. Adam RA, Adam YG. Malignant ascites: past, present, and future. J Am Coll Surg. 2004;198(6):999-1011.

16. Qazi R, Savlov ED. Peritoneovenous shunt for palliation of malignant ascites. Cancer. 1982;49(3):600-602.

17. Ariel IM, Oropeza R, Pack GT. Intracavitary administration of radioactive isotopes in the control of effusions due to cancer. Results in 267 patients. Cancer. 1966;19(8):1096-1102.

18. Runyon BA. Care of patients with ascites. N Engl J Med. 1994;330(5): 337-342.

19. Gotlieb WH, Feldman B, Feldman-Moran O, et al. Intraperitoneal pressures and clinical parameters of total paracentesis for palliation of symptomatic ascites in ovarian cancer. Gynecol Oncol. 1998;71(3): 381-385.

20. Becker G, Galandi D, Blum HE. Malignant ascites: systematic review and guideline for treatment. Eur J Cancer. 2006;42(5):589-597.

21. Keen A, Fitzgerald D, Bryant A, Dickinson HO. Management of drainage for malignant ascites in gynaecological cancer. Cochrane Database Syst Rev. 2010;1:CD007794.

22. Stark RH, Sauter KE. Surgical treatment of adenocarcinoma of the stomach in a community hospital. Surg Gynecol Obstet. 1985;160(2):153-156.

23. Ostrowski MJ, Halsall GM. Intracavitary bleomycin in the management of malignant effusions: a multicenter study. Cancer Treat Rep. 1982;66(11):1903-1907.

24. Maat B, Oosterlee J, Spaas JA, White H, Lammes FB. Dissemination of tumour cells via LeVeen shunt. Lancet. 1979;1(8123):988.

25. Paladine W, Cunningham TJ, Sponzo R, Donavan M, Olson K, Horton J. Intracavitary bleomycin in the management of malignant effusions. Cancer. 1976;38(5):1903-1908.

26. Burger RA. Antiangiogenic agents should be integrated into the standard treatment for patients with ovarian cancer. Ann Oncol. 2011;22 Suppl 8:viii65-viii68.

27. Burger RA. Overview of anti-angiogenic agents in development for ovarian cancer. Gynecol Oncol. 2011;121(1):230-238.

28. Ferrara N. VEGF as a therapeutic target in cancer. Oncology. 2005; 69 Suppl 3:11-16.

29. Monk BJ, Han E, Josephs-Cowan CA, Pugmire G, Burger RA. Salvage bevacizumab (rhuMAB VEGF)-based therapy after multiple prior cytotoxic regimens in advanced refractory epithelial ovarian cancer. Gynecol Oncol. 2006;102(2):140-144.

30. Paley PJ, Staskus KA, Gebhard K, et al. Vascular endothelial growth factor expression in early stage ovarian carcinoma. Cancer. 1997;80(1):98-106.

31. Senger DR, Van de Water L, Brown LF, et al. Vascular permeability factor (VPF, VEGF) in tumor biology. Cancer Metastasis Rev. 1993; 12(3-4):303-324.

32. Ferrara N. Molecular and biological properties of vascular endothelial growth factor. J Mol Med (Berl). 1999;77(7):527-543.

33. Ferrara N. Role of vascular endothelial growth factor in the regulation of angiogenesis. Kidney Int. 1999;56(3):794-814.

34. Ferrara N. Vascular endothelial growth factor: molecular and biological aspects. Curr Top Microbiol Immunol. 1999;237:1-30.

35. Ferrara N, Kerbel RS. Angiogenesis as a therapeutic target. Nature. 2005;438(7070):967-974.
36. Shalaby F, Rossant J, Yamaguchi TP, et al. Failure of blood-island formation and vasculogenesis in Flk-1-deficient mice. Nature. 1995; 376(6535):62-66.

37. Zebrowski BK, Liu W, Ramirez K, Akagi Y, Mills GB, Ellis LM. Markedly elevated levels of vascular endothelial growth factor in malignant ascites. Ann Surg Oncol. 1999;6(4):373-378.

38. Byrne AT, Ross L, Holash J, et al. Vascular endothelial growth factortrap decreases tumor burden, inhibits ascites, and causes dramatic vascular remodeling in an ovarian cancer model. Clin Cancer Res. 2003;9(15):5721-5728.

39. Xu L, Yoneda J, Herrera C, Wood J, Killion JJ, Fidler IJ. Inhibition of malignant ascites and growth of human ovarian carcinoma by oral administration of a potent inhibitor of the vascular endothelial growth factor receptor tyrosine kinases. Int J Oncol. 2000;16(3):445-454.

40. Stoelcker B, Echtenacher B, Weich HA, Sztajer H, Hicklin DJ, Mannel DN. VEGF/Flk-1 interaction, a requirement for malignant ascites recurrence. J Interferon Cytokine Res. 2000;20(5):511-517.

41. Kobold S, Hegewisch-Becker S, Oechsle K, Jordan K, Bokemeyer C, Atanackovic D. Intraperitoneal VEGF inhibition using bevacizumab: a potential approach for the symptomatic treatment of malignant ascites? Oncologist. 2009;14(12):1242-1251.

42. Numnum TM, Rocconi RP, Whitworth J, Barnes MN. The use of bevacizumab to palliate symptomatic ascites in patients with refractory ovarian carcinoma. Gynecol Oncol. 2006;102(3):425-428.

43. Hamilton CA, Maxwell GL, Chernofsky MR, Bernstein SA, Farley JH, Rose GS. Intraperitoneal bevacizumab for the palliation of malignant ascites in refractory ovarian cancer. Gynecol Oncol. 2008;111(3):530-532.

44. Kesterson JP, Mhawech-Fauceglia P, Lele S. The use of bevacizumab in refractory ovarian granulosa-cell carcinoma with symptomatic relief of ascites: a case report. Gynecol Oncol. 2008;111(3):527-529.

45. Stewart MW, Grippon S, Kirkpatrick P. Aflibercept. Nat Rev Drug Discov. 2012;11(4):269-270.

46. Stewart MW. Aflibercept (VEGF trap-eye): the newest anti-VEGF drug. Br J Ophthalmol. March 23, 2012. [Epub ahead of print.]

47. Kim ES, Serur A, Huang J, et al. Potent VEGF blockade causes regression of coopted vessels in a model of neuroblastoma. Proc Natl Acad Sci U S A. 2002;99(17):11399-11404.

48. Huang J, Frischer JS, Serur A, et al. Regression of established tumors and metastases by potent vascular endothelial growth factor blockade. Proc Natl Acad Sci U S A. 2003;100(13):7785-7790.

49. Hu L, Hofmann J, Holash J, Yancopoulos GD, Sood AK, Jaffe RB. Vascular endothelial growth factor trap combined with paclitaxel strikingly inhibits tumor and ascites, prolonging survival in a human ovarian cancer model. Clin Cancer Res. 2005;11(19 Pt 1):6966-6971.

50. Lockhart AC, Rothenberg ML, Dupont J, et al. Phase I study of intravenous vascular endothelial growth factor trap, aflibercept, in patients with advanced solid tumors. J Clin Oncol. 2010;28(2):207-214.

51. Gaya A, Tse V. A preclinical and clinical review of aflibercept for the management of cancer. Cancer Treat Rev. January 19, 2012. [Epub ahead of print.]

52. Teng LS, Jin KT, He KF, Zhang J, Wang HH, Cao J. Clinical applications of VEGF-trap (aflibercept) in cancer treatment. $J$ Chin Med Assoc. 2010;73(9):449-456.

53. Colombo N, Mangili G, Mammoliti S, et al. A Phase II study of aflibercept in patients with advanced epithelial ovarian cancer and symptomatic malignant ascites. Gynecol Oncol. 2012;125(1): $42-47$.

54. Gotlieb WH, Amant F, Advani S, et al. Intravenous aflibercept for treatment of recurrent symptomatic malignant ascites in patients with advanced ovarian cancer: a Phase 2, randomised, double-blind, placebocontrolled study. Lancet Oncol. 2012;13(2):154-162.

55. Ruf $\mathrm{P}$, Lindhofer $\mathrm{H}$. Induction of a long-lasting antitumor immunity by a trifunctional bispecific antibody. Blood. 2001;98(8):2526-2534.

56. Zeidler R, Mysliwietz J, Csanady M, et al. The Fc-region of a new class of intact bispecific antibody mediates activation of accessory cells and NK cells and induces direct phagocytosis of tumour cells. Br J Cancer. 2000;83(2):261-266. 
57. Heiss MM, Murawa P, Koralewski P, et al. The trifunctional antibody catumaxomab for the treatment of malignant ascites due to epithelial cancer: Results of a prospective randomized Phase II/III trial. Int $J$ Cancer. 2010;127(9):2209-2221.

58. Heiss MM, Strohlein MA, Jager M, et al. Immunotherapy of malignant ascites with trifunctional antibodies. Int J Cancer. 2005;117(3): 435-443.

59. Burges A, Wimberger P, Kumper C, et al. Effective relief of malignant ascites in patients with advanced ovarian cancer by a trifunctional anti-EpCAM x anti-CD3 antibody: a phase I/II study. Clin Cancer Res. 2007;13(13):3899-3905.
60. Pietzner K, Jager M, Schoberth A, et al. First patient treated with a re-challenge of catumaxomab in recurrent malignant ascites: a case report. Med Oncol. 2012;29(2):1391-1396.

61. K. El-Shami AE, Y. El-Kerm. Open-label safety and efficacy pilot trial of intraperitoneal bevacizumab as palliative treatment in refractory malignant ascites. J Clin Oncol. 2007;25(No. 18S (June 20 Supplement)):9043.

\section{Publish your work in this journal}

The International Journal of Women's Health is an international, peerreviewed open-access journal publishing original research, reports, reviews and commentaries on all aspects of women's healthcare including gynecology, obstetrics, and breast cancer. Subject areas include: Chronic conditions (migraine headaches, arthritis, osteoporosis);
Endocrine and autoimmune syndromes; Sexual and reproductive health; Psychological and psychosocial conditions. The manuscript management system is completely online and includes a very quick and fair peer-review system. Visit http://www.dovepress.com/ testimonials.php to read real quotes from published authors. 